\section{Da Necessidade da Ratificação da Convenção n. 87 OIT pelo Brasil}

\section{Need for ILO Convention 87 Ratification in Brazil}

\section{Resumo}

O presente estudo tem por escopo demonstrar a necessidade da ratificação da Convenção n. 87 da OIT que reza a liberdade sindical e a proteção ao direito de sindicalização, haja vista que vivemos em um Estado Democrático de Direito, sendo assim, é de se pressupor a valoração de direitos fundamentais, como a liberdade sindical. Embora - Brasil seja signatário da aludida Convenção, ficamos obstados de ratificá-la devido a limitações impostas pela Constituição Federal vigente, que nos impõe a unicidade sindical por categoria e a contribuição sindical compulsória, de modo a obstar a universalização do princípio da liberdade sindical. A Convenção n. 87 é o mais importante documento internacional sobre liberdade sindical em virtude de sua especificidade e abrangência, haja vista que ela visa garantir a liberdade sindical em face aos poderes públicos. A liberdade sindical pressupõe assegurar um direito humano, e deve ser dada a empregados e empregadores a opção para se organizar livremente sem quaisquer intervenções do Estado, e gozar dessa ampla liberdade pressupõe poder filiar-se e manter-se filiado aos sindicatos, desde que haja um interesse das partes. A liberdade sindical no Brasil pressupõe a ratificação da Convenção n. 87 da OIT.

Palavras-chave: direito sindical; liberdade sindical; reforma sindical.

\section{Abstract}

The purpose of this study is to demonstrate the need for ratification of Convention n. 87, which provides for freedom of association and the right to organize protection, given that we live in a Democratic Governance and Rule of Law, fundamental rights, such as freedom of association, must be considered. Although Brazil is a signatory to the aforementioned Convention, we have been unable to ratify it due
Prof. ${ }^{a}$ Dr. ${ }^{a}$. Elessandra dos Santos Marques Válio

Doutora em Direito pela Pontifícia Universidade Católica de São Paulo PUC-SP, Professora no Grupo Educacional Drummond. Professora Assistente no curso de Especialização em Direito do Trabalho Material e Processual na PUC-SP.

E-mail: elessandra@ valio.adv.br 
to limitations imposed by the current Federal Constitution, which imposes union unity by category and compulsory union contribution, in order to prevent universalization of freedom of association principle. Convention n. 87 is the most important international document on freedom of association because of its specificity and scope, since it aims to guarantee freedom of association vis-à-vis public authorities. Freedom of association presupposes ensuring a human right, and employees and employers should be given the option to organize freely without any intervention by the State, and to enjoy this broad freedom presupposes being able to join and remain affiliated to trade unions, provided there is interest of the parties. Freedom of association in Brazil presupposes the ratification of Convention 87.

Keywords: trade union rights; freedom of association; trade union reform.

\section{Introdução}

A liberdade sindical é considerada um elemento imprescindível de um Estado Democrático de Direito.

Embora prevista há muitos anos por vários documentos internacionais importantes, como a Declaração sobre os objetivos da Organização Internacional do Trabalho (Filadélfia, 1944), na Declaração Universal dos Direitos do Homem (Nova York, 1948) e no Pacto Social dos Direitos Econômicos, Sociais e Culturais (Nova York, 1966), a Convenção n. 87 da OIT (São Francisco, 1948) e a Convenção n. 98 da OIT (Genebra, 1949), a liberdade sindical é limitada em nosso país.

A vigência do art. $8^{\circ}$, incisos II e IV da Constituição Federal de 1988 obsta a ratificação do documento internacional mais importante a respeito de liberdade sindical, a Convenção n. 87 da OIT. O Brasil é o único país da América Latina que ainda não ratificou o aludido documento.

\section{A Proteção da Liberdade Sindical no Cenário Internacional}

Após o final da Primeira Guerra Mundial, surge a Organização Internacional do Trabalho (OIT) como um organismo especializado nas questões juslaborais e sociais no âmbito da Organização das Nações Unidas (ONU), reconhecendo a precípua importância no que tange à promoção e proteção dos direitos humanos do trabalhador. Seu surgimento deparou-se com o direito de sindicalização e o sindicalismo bastante arraigados nos países industrialmente desenvolvidos e começando a se difundir em outros países em processo de desenvolvimento incipiente.

Em 1944, a Declaração da Filadélfia' foi outorgada tendo por escopo a busca da paz, a justiça social e condições mais dignas e justas aos trabalhadores. Tal declaração já anunciou o direito à liberdade sindical.

A Declaração Universal dos Direitos Humanos das Nações Unidas de 1948, cujo texto estabeleceu que todas as pessoas nascem livres, iguais em dignidade e direitos, por serem dotadas de razão, devem agir umas em relação às outras com espírito de fraternidade. A mesma declaração elevou a liberdade sindical ao patamar de direito humano ${ }^{2}$, passando a ser considerada um elemento essencial no sistema das relações profissionais, bem como da democracia política. Nesse mesmo ano, foi aprovada a Convenção n.87, que foi a primeira convenção da Organização Internacional do Trabalho que regulamentou amplamente a liberdade sindical.

Cumpre ressaltar a importância do conceito de liberdade em sentido lato sensu, levando- se em conta as possibilidades de ação e de escolhas, nas palavras de Caio Prado Júnior:

\footnotetext{
1 A Declaração da Filadélfia constitui ANEXO da Constituição da Organização Internacional do Trabalho.

2 Artigo $X X$

1. Toda pessoa tem direito à liberdade de reunião e associação pacíficas.

2. Ninguém pode ser obrigado a fazer parte de uma associação.
} 
(...) "liberdade" se entende a faculdade, a possiblidade e a oportunidade de o indivíduo se realizar, isto é, dar vazão às suas potencialidades e fixar em função delas suas aspirações, logrando alcançá-las. A liberdade não é, em si, senão um meio, e não um fim. Fim esse que não pode ser outro, para o indivíduo, que aquela realização de sua personalidade. (Prado Jr., 2008, p. 59)

Robert Alexy faz uma salutar observação a respeito do direito geral de liberdade, pois assevera que tal conjunto de normas pode se estender além da proteção de ações, mas também ser estendido à tutela de situações e posições jurídicas do titular dos direitos fundamentais. Portanto, o ordenamento jurídico em questão não protege apenas o seu 'fazer', mas também o seu "ser" fático e jurídico. (Alexy, 2006, p. 344-345).

Embora abrangente o conceito de liberdade, podemos depreender que a liberdade é intrínseca ao ser humano enquanto animal social, na medida em que a complexidade das relações sociais pressupõe que cada indivíduo tenha, cada vez mais, opções de escolhas políticas e de expressão socioeconômica. A liberdade não pode ser uma abstração jurídica desprovida de efetividade.

No que tange especificamente a liberdade sindical, Canotilho e Vital Moreira asseveram que

(...) é hoje mais que uma simples liberdade de associação perante o Estado. Verdadeiramente, o centro tônico coloca-se no direito à actividade sindical, perante o Estado e perante o patronado, o que implica, por um lado, o direito de não ser prejudicado pelo exercício de direitos sindicais e, por outro lado, o direito a condições de actividade sindical (direito de informação e de assembleia nos locais de trabalho, dispensa de trabalho para dirigentes e delegados sindicais). Finalmente, dada sua natureza de organização de classe, os sindicatos possuem uma importante dimensão política que se alarga muito para além dos interesses profissionais dos sindicalizados, fazendo com que a liberdade sindical consista também ao direito dos sindicatos a exercer determinadas funções políticas. (Canotilho, 1993, p. 300)

Destarte, a liberdade é pressuposto metajurídico fundamental do Estado Democrático de Direito, um requisito para a preservação da cidadania e da estabilidade política das relações sociais, negá-la é atentar contra a História, a Ciência Política e ao próprio Direito.

\section{A Evolução Sindical no Brasil}

No que concerne à evolução sindical no Brasil, a Constituição do Império de 1822 assegurava somente a liberdade para o trabalho (art. 174, inciso $X X \mathrm{IV}^{3}$ ). Insta não nos olvidarmos que até 1888 vigia a escravidão, sendo que as relações de emprego se davam em sua grande parte no setor cafeeiro nos Estados do Rio de Janeiro e São Paulo.

Em 1889, com a Proclamação da República, inspirada na ideologia da Revolução Francesa, a Constituição da República de 1891 trazia em seu art.72, parágrafo $8^{\circ}$ a liberdade de associação, e no parágrafo 24 a liberdade de exercício profissional ${ }^{4}$.

3 Art. 179. A inviolabilidade dos Direitos Civis, e Políticos dos Cidadãos Brazileiros, que tem por base a liberdade, a segurança individual, e a propriedade, é garantida pela Constituição do Império, pela maneira seguinte. [...]

XXIV. Nenhum genero de trabalho, de cultura, industria, ou commercio póde ser prohibido, uma vez que não se opponha aos costumes publicos, á segurança, e saude dos Cidadãos.

(http://www.planalto.gov.br/ccivil_03/constituicao/ constituicao24.htm acesso em 06.09.2018)

4 Art 72 - A Constituição assegura a brasileiros e a estrangeiros residentes no País a inviolabilidade dos direitos concernentes à liberdade, à segurança individual e à propriedade, nos termos seguintes:

$\S 8^{\circ}-$ A todos é lícito associarem-se e reunirem-se livremente e sem armas; não podendo intervir a polícia senão para manter a ordem pública.

$\S 24$ - É garantido o livre exercício de qualquer profissão moral, intelectual e industrial. 
A primeira lei que se referiu aos sindicatos no Brasil foi a Lei n.979 de 1903, porém, tal dispositivo legal apenas aludia à organização dos sindicatos rurais, à distribuição dos créditos oficiais aos associados e à organização de cooperativas para a venda dos produtos. 5

O Decreto n. 1.637 de $1907^{\circ}$ garantia o direito de sindicalização para todos os trabalhadores e ainda assegurava a formação das cooperativas, bem como permitia o desenvolvimento e defesa dos interesses profissionais de seus membros.

No ano de 1930, sob o comando de Lindolfo Collor, é criado o Ministério da Indústria e Comércio, tendo por fulcro o Decreto n. 19.443 de novembro de 1930. O referido órgão da Administração Pública Direta tinha como atribuição implementar a política trabalhista e administrar a organização dos trabalhadores como força de cooperação com o Estado.

No período de 1931 a 1935, a unicidade e a pluralidade tornaram-se inconstantes, ou seja, com o Decreto n. 19.770, de 19 de marco de 1931, mais precisamente em seu artigo 9o, consagrou a unicidade sindical, bem como a neutralidade e a nacionalidade dos sindicatos, que foi alterada devido a Carta Constitucional de 1934, que acolheu a pluralidade, bem como a liberdade e autonomia sindical, o que durou pouco, pois - governo federal imediatamente retomou seu controle pleno, através do estado de sítio de 1935, continuado pela ditadura aberta de 1937, eliminando, assim, qualquer foco de resistência à sua estratégia político-jurídica, firmando solidamente a larga estrutura do modelo justrabalhista, cujas bases iniciara logo após o movimento de outubro de 1930 (Delgado, 2007, p. 1361).

5 DECRETO N 979, DE 6 DE JANEIRO DE 1903

Faculta aos profissionais da agricultura e industrias ruraes a organização de sindicatos para defesa de seus interesses. http://www.planalto.gov.br/ccivil_03/decreto/ Antigos/D0979.htm [acesso em 06.09.2018].

6 DECRETO N. 1637 - DE 5 DE JANEIRO DE 1907

Crea sindicatos profissionaes e sociedades cooperativas. http://www6.senado.gov.br/legislacao/ListaPublicacoes.action?id=55323 [acesso em 06.09.2018].
A unicidade sindical foi introduzida no Brasil pelo Decreto-lei n. 1.402 de 05 de julho de 1939, em seu art. 6", cuja redação era: "Não será reconhecido mais de um sindicato para cada profissão".

Com a aprovação da Consolidação das Leis do Trabalho em 1943, ainda na vigência da Constituição de 1937, houve a reprodução da legislação sindical existente, pois reza o art. 516 da CLT: "Não será reconhecido mais de um sindicato representativo da mesma categoria econômica ou profissional, profissão liberal, em uma dada base territorial", fazendo com que exista um contraste com a sistematização das leis do primeiro período da revolução de 1930 e também com o preenchimento das lacunas legislativas existentes. A inspiração para tanto veio das convenções da Organização Internacional do Trabalho, da encíclica Rerum Novarum e das conclusões do Primeiro Congresso de Direito Social (São Paulo, 1941). (Sussekind, 2010, p. 372-373).

Em 18 de setembro de 1946, a Constituição então promulgada albergou a proteção aos direitos individuais e reconheceu o regime democrático. Já em relação às questões atinentes à organização sindical e ao exercício de greve, deixou a cargo de leis ordinárias.

A Carta Maior de 1967 seguiu a mesma linha da norma anterior no que diz respeito ao sindicalismo, porém, a Emenda Constitucional n. 1/69 vedou a greve nas atividades essenciais e nos serviços públicos ${ }^{8}$.

\section{A Constituição Federal de 1988 e os Limites para a Ratificação da Convenção n. 87 da OIT.}

A atual Constituição da República Federativa do Brasil representou um marco da redemocratização, pois abrangeu vários aspectos dos direitos fundamentais, todavia, no que se refere à liberdade sindical, restringiu-se a assegurar a liberdade de associação, bem como a atuação

7 Decreto-lei n. 9.070/46 e Lei n. 4.330/64.

8 Art. 157, § 7o, CF/67. 
do dirigente sindical ${ }^{9}$, e ainda a sindicalização dos servidores públicos civis ${ }^{10}$.

Houve ainda a manutenção da unicidade sindical por categoria e da contribuição sindical compulsória em prol das associações que integram o sistema confederativo, conforme dispõem incisos II e IV do art. $8^{\circ}$ da Carta Maior. Destarte, tais dispositivos constitucionais obstam a universalização do princípio da liberdade sindical, consagrada por vários instrumentos internacionais, dentre eles a Convenção n. 87 da Organização Internacional do Trabalho.

9 Art. $8^{\circ}$ É livre a associação profissional ou sindical, observado o seguinte:

I - a lei não poderá exigir autorização do Estado para a fundação de sindicato, ressalvado o registro no órgão competente, vedadas ao Poder Público a interferência e a intervenção na organização sindical;

II - é vedada a criação de mais de uma organização sindical, em qualquer grau, representativa de categoria profissional ou econômica, na mesma base territorial, que será definida pelos trabalhadores ou empregadores interessados, não podendo ser inferior à área de um Município;

III - ao sindicato cabe a defesa dos direitos e interesses coletivos ou individuais da categoria, inclusive em questões judiciais ou administrativas;

IV - a assembleia geral fixará a contribuição que, em se tratando de categoria profissional, será descontada em folha, para custeio do sistema confederativo da representação sindical respectiva, independentemente da contribuição prevista em lei;

$V$ - ninguém será obrigado a filiar-se ou a manter-se filiado a sindicato;

VI - é obrigatória a participação dos sindicatos nas negociações coletivas de trabalho;

VII - o aposentado filiado tem direito a votar e ser votado nas organizações sindicais;

VIII - é vedada a dispensa do empregado sindicalizado a partir do registro da candidatura a cargo de direção ou representação sindical e, se eleito, ainda que suplente, até um ano após o final do mandato, salvo se cometer falta grave nos termos da lei.

Parágrafo único. As disposições deste artigo aplicam-se à organização de sindicatos rurais e de colônias de pescadores, atendidas as condições que a lei estabelecer. [grifo nosso]

10 Art. 37. A administração pública direta e indireta de qualquer dos Poderes da União, dos Estados, do Distrito Federal e dos Municípios obedecerá aos princípios de legalidade, impessoalidade, moralidade, publicidade e eficiência e, também, ao seguinte:

[...]

VI - é garantido ao servidor público civil o direito à livre associação sindical;
Nas palavras de Amauri Mascaro do Nascimento,

A Constituição de 1988 manteve defeitos, advindos do corporativismo, introduziu conceitos indeterminados e sobrepôs uma nova ordem legal à CLT, nem sempre clara, permitindo divergências de interpretação. Não há como situá-la no plano da liberdade sindical: veda mais de um sindicato, da mesma categoria, na mesma base territorial. Seria um marco no sentido da autonomia coletiva se não cometesse esse pecado. A autonomia coletiva pressupõe o espaço de liberdade que a Constituição de 1988 não permite totalmente. (Nascimento, 2008, 178-179).

A liberdade sindical é um pressuposto imprescindível do Estado Democrático de Direito, um dos alicerces de todo o sistema das relações de trabalho, bem como outros direitos também fundamentais relacionados especificamente com a pessoa humana trabalhadora, possibilita a ação sindical dos trabalhadores de maneira ordenada, visando às melhorias para cada categoria.

Sobre a liberdade sindical, Arnaldo Sussekind ressalta que tomando por base o direito comparado, inclusive a Convenção n. 87 da OIT, a liberdade sindical deve ser compreendida sob um tríplice aspecto:

a) liberdade sindical coletiva, que corresponde ao direito dos grupos de empresários e de trabalhadores, vinculados por uma atividade comum, similar ou conexa, de construir o sindicato de sua escolha, com a estrutura que thes convier;

b) liberdade sindical individual, que é o direito de cada trabalhador ou empresário de filiar-se ao sindicato de sua preferência, representativo do grupo a que pertence, e dele desligar-se;

c) autonomia sindical, que concerne à liberdade de organização interna e de funcionamento da associação sindical e, bem assim, à faculdade de constituir federações e confederações ou filiar-se às já existentes, visando sempre os fins que fundamentam sua instituição. (Sussekind, 2010, p. 374) 
Diante do exposto, podemos notar que a Constituição Federal vigente, embora assegure a atuação sindical nos âmbitos judicial e administrativo, restringe a liberdade sindical obstando a formação organizacional dos sindicatos nos moldes desejados por empregados e empregadores, via unicidade sindical e contribuição compulsória.

Sobre a liberdade sindical no Brasil, Amauri Mascaro do Nascimento disserta:

\begin{abstract}
Avaliando sob o prisma legal, o sistema brasileiro não pode ser enquadrado entre os de plena liberdade sindical porque a lei não atende ao primeiro subprincípio da ideia de liberdade sindical, o direito de constituir, sem necessidade de prévia autorização do Estado, entidades sindicais, julgadas convenientes pelos próprios interessados, trabalhadores ou empresários, bem como o direito complementar de filiação, positivo ou negativo, nessas associações, entende-se como direito positivo o de ingressar e negativo o de sair da entidade livremente; assim, não há como compatibilizar o nosso sistema com a liberdade plena porque nele é proibido criar mais de um sindicato na mesma base territorial e categoria com o que a autonomia das entidades sindicais é comprometida com essa proibição. (Nascimento, 2008, p. 184)
\end{abstract}

Insta citarmos algumas normas atinentes à liberdade sindical inseridas na Declaração sobre os objetivos da Organização Internacional do Trabalho (Filadélfia, 1944), na Declaração Universal dos Direitos do Homem (Nova York, 1948) e no Pacto Social dos Direitos Econômicos, Sociais e Culturais (Nova York, 1966), a já citada Convenção n. 87 da OIT (São Francisco, 1948) e a Convenção n. 98 da OIT (Genebra, 1949).

Indubitavelmente o mais importante desses documentos é a Convenção n. 87, assim deve ser considerada, em virtude de sua especificidade e abrangência, haja vista que ela visa garantir a liberdade sindical em face aos poderes públicos. Aludido documento foi complementado pela Convenção n. 98, a qual, por sua vez tem por fulcro a proteção dos direitos sindicais frente aos empregadores e respectivas organizações.
Vale mencionar que a Convenção n. 98 assevera a independência das associações sindicais de trabalhadores em face às associações de empregadores e vice-versa, e também incentiva a negociação coletiva (Sussekind, 2010).

A Convenção n. 87 da OIT representa a expressão internacional da autonomia e liberdade sindical. Consagra direitos de empregados e empregadores, os quais podem sem qualquer distinção ou autorização prévia constituir as organizações que lhes forem oportunas, bem como filiar-se ou não a tais organizações. Essas associações têm por objetivos a defesa e promoção de interesses de seus respectivos filiados. Tal convenção, como muito bem ressalta José Carlos (Arouca, 2009, p. 81-82), elege as seguintes liberdades de:

a. constituir associações, independentemente de prévia autorização;

b. filiação, condicionada apenas à aceitação de seus estatutos;

c. elaboração de estatuto e regulamentos, bem como dos programas administrativos e de ação;

d. eleição livre de seus representantes;

e. proibir ao Estado de intervir, administrativamente suspendendo ou dissolvendo as organizações;

f. as organizações se constituírem em federações e confederações e de filiarem-se a elas, e ainda, liberdade para que tais organizações filiem-se a outras internacionais;

g. granjear personalidade jurídica sem quaisquer óbices ou limitações das garantias de autonomia;

h. estender as liberdades supracitadas, mediante lei ordinária, às forças armadas e à polícia;

i. o Estado adotar medidas assecuratórias do livre exercício do direito sindical, seja por empregados ou empregadores. 
A Convenção n. 87 é a principal norma protetora da liberdade sindical, entretanto, não foi ratificada pelo Brasil devido às limitações constitucionais dos incisos II (unicidade) e IV (contribuição compulsória) do art. $8^{\circ}$, que são vestígios deixados pela ditadura na Carta Maior vigente. Embora tal norma tenha a democracia como fundamento precípuo e o Brasil tenha sido um de seus signatários, não a ratificou e nem poderá ratificá-la, enquanto o Texto Maior permanecer com os incisos II e IV do art. $8^{\circ} \mathrm{em}$ vigor.

Como bem recorda José Carlos Arouca,

Em 31 de maio de 1949, o Presidente Dutra acolheu a exposição de motivos de seu Chanceler, Ciro de Freitas Vale, para encaminhar ao Congresso Nacional propondo sua aprovação (Convenção n. 87 da OIT), que teve tramitação morosa e vergonhosa. Melhor dizendo, até 1966, praticamente não tramitou. Ao contrário, desapareceu. Reconstituída, foi encaminhada à Comissão de Legislação Social, que solicitou a manifestação do Ministério do Trabalho. A resposta só veio em 1968, após a audiência da Comissão Permanente de Direito Social. Em 1970, outra vez foi reconstituída, pois conhecera uma segunda e estranha desaparição. Finalmente, em agosto de 1985, foi aprovado o então deputado Francisco Amaral, favorável à sua ratificação. Depois, aprovada na Câmara Federal foi remetida à Comissão de Relações Exteriores do Senado. Apostava-se na sua rápida aprovação porque o Brasil fora incluído na "lista negra" da OIT, como filiado faltoso. Somente em 11 de dezembro de 2002 a Comissão de Constituição e Justiça do Senado aprovou o Projeto de Decreto Legislativo n. 16, de 12.09.1984, seguindo o parecer do Senador José Eduardo Dutra, abrindo caminho para a apreciação da matéria no plenário. (Arouca, 2009, p. 83-84)

Em relação à aprovação da Convenção n. 87, Arnaldo Sussekind disserta: "A Câmara dos Deputados, numa decisão equivocada, chegou a aprová-la; mas o Senado Federal não homologou até hoje, essa aprovação, que seria, data vênia, inconstitucional." (Sussekind, 2010, p. 375)

\section{Fórum Nacional do Trabalho (FNT) e a PEC 369/2005}

Em 29 de julho de 2003, o Decreto n. 4.796 instituiu o Fórum Nacional do Trabalho (FNT) com representantes dos empregadores, trabalhadores e governo, e o objetivo da criação desse fórum é a negociação de propostas para a Reforma Sindical e Trabalhista no Brasil.

O FNT tem por escopo promover a democratização das relações de trabalho via adoção de um sistema de organização sindical pautado na autonomia e na liberdade, que possa atualizar a legislação laboral e concomitantemente, gerar emprego e renda. O Fundo também pretende modernizar as instituições de regulação do trabalho, especialmente a Justiça do Trabalho e o Ministério do Trabalho e Emprego; estimular o diálogo e o tripartismo e assegurar a justiça social no âmbito das leis trabalhistas, da solução de conflitos e das garantias sindicais.

A reforma sindical tem gerado grandes embates em toda sociedade, sua indispensabilidade é notória, todavia, um dos entraves para tanto é adequar interesses diversos e a conformidade com a Constituição Federal e os tratados internacionais de proteção dos direitos humanos dos trabalhadores, haja vista, que em um Estado Democrático de Direito deve referenciar a materialização da democracia e a proteção dos direitos fundamentais.

No que tange à liberdade sindical, já foram apresentadas propostas de Emenda Constitucional ao Congresso Nacional, a mais recente é a PEC n. 369/2005, que desde novembro de 2011 está aguardando parecer na Comissão de Constituição, Justiça e de Cidadania. Essa PEC prevê a alteração dos artigos $8^{\circ}, 11,37$ e 114; essa modificação é imprescindivel para qualquer reforma sindical, pois, apenas com a alteração do art. $8^{\circ}$ seria possivvel a ratificação da Convenção n. 87 da OIT.

A PEC n. 359/69 nos traz um modelo de pluralismo restrito, tendo por base o princípio do sindicato representativo e a concentração do poder na cúpula sindical, ceifando a função dos sindicatos que não atinjam o status de representatividade. Concede também poderes 
ao Ministério do Trabalho para reconhecer tal representatividade das entidades, bem como a definição dos ramos de atividades.

A proposta também denota o fim da contribuição sindical compulsória, mas permite que o empregador desconte na folha de pagamento e recolha em favor das organizações sindicais as contribuições associativas, que custearão o sistema confederativo.

A Organização Internacional do Trabalho tem pressionado o Brasil a ratificar a Convenção n. 87, mas certo é que, na condição de uma economia mundial promissora e tentando granjear cada vez mais destaque no cenário mundial, nos parece um dissenso a não ratificação do referido diploma.

\section{Considerações Finais}

Ante tudo que foi exposto, faz-se necessário ressaltarmos os seguintes pontos:

1. Em 1919 surge a Organização Internacional do Trabalho como um órgão especializado nas questões juslaborais e sociais, reconhecendo a necessidade da promoção e proteção do trabalhador, sua criação já encontrou a sindicalização e o sindicalismo nos países industrialmente desenvolvidos.

2. No ano de 1944 a Declaração da Filadélfia é outorgado, tendo por objetivo a busca da paz, a justiça social e condições mais dignas e justas aos trabalhadores, anunciando o direito à liberdade sindical.

3. A Declaração Universal dos Direitos Humanos de 1948 elevou a liberdade sindical ao patamar de direito humano, passando a ser considerado com um elemento essencial nos sistemas das relações profissionais.

4. Ainda em 1948, a Organização Internacional do Trabalho aprova a Convenção n. 87, que foi a primeira convenção que regulamentou de forma ampla a liberdade sindical.
5. Nas Constituições brasileiras, a Carta de 1889 foi a primeira a trazer a liberdade sindical em seu texto, art. 72, parágrafo $8^{\circ}$.

6. A primeira lei sobre os sindicatos no Brasil foi a Lei n. 979/1903, todavia, tratava apenas da organização dos sindicatos rurais, distribuição dos créditos aos associados e à organização de cooperativas para a venda de produtos.

7. O Decreto n. 1.637 de 1907 garantia o direito de sindicalização para todos os trabalhadores e ainda assegurava a formação das cooperativas, bem como permitia o desenvolvimento e defesa dos interesses profissionais de seus membros.

8. Em 1930 é criado o Ministério da Indústria e Comércio com a atribuição de implementar a política trabalhista e administrar a organização dos trabalhadores, com a cooperação do Estado.

9. Introduzida no Brasil pelo Decreto-lei $n$. 1.402/1939, a unicidade sindical foi mantida na Consolidação das Leis do Trabalho em 1943.

10. A Constituição da República vigente reza a unicidade sindical por categoria e a contribuição sindical compulsória, entretanto, os incisos II e IV do art. $8^{\circ}$ obstam a universalização do princípio da liberdade sindical.

11. A liberdade sindical é um pressuposto imprescindivel do Estado Democrático de Direito, um dos alicerces de todo o sistema das relações de trabalho, bem como outros direitos também fundamentais relacionados especificamente com a pessoa humana trabalhadora, possibilita a ação sindical dos trabalhadores de maneira ordenada, visando às melhorias para cada categoria.

12. Embora a Constituição Federal de 1988 assegure a atuação sindical nos âmbitos judicial e administrativo, restringe a liberdade sindical obstando a formação organizacional dos sindicatos nos moldes desejados por 
empregados e empregadores, via unicidade sindical e contribuição compulsória.

13. A Convenção n. 87 é o mais importante documento internacional sobre liberdade sindical em virtude de sua especificidade e abrangência, haja vista que ela visa garantir a liberdade sindical em face aos poderes públicos. Aludido documento foi complementado pela Convenção n. 98, a qual, por sua vez, tem por fulcro a proteção dos direitos sindicais frente aos empregadores e respectivas organizações.

14. O Brasil, apesar de ser signatário da Convenção n. 87 da OIT, não a ratificou, pois nossa Constituição vigente em seu art. $8^{\circ}$, incisos II e IV, é empecilho para tal ratificação.

15. O Decreto $n, 4.796$ de 2003 criou o Fórum Nacional do Trabalho com representantes de empregados, empregadores e governo, e tem por objetivo a negociação de Propostas para a Reforma Sindical e Trabalhista no Brasil.

16. Considerando os óbices constitucionais para a ratificação da Convenção n. 87 da OIT, já foram apresentadas algumas propostas de Emendas à Constituição, a mais recente é a PEC n. 369/2005, que atualmente está aguardando parecer da Comissão de Constituição, Justiça e Cidadania. Tal PEC prevê a alteração dos artigos $8^{\circ}, 11,37$ e 114, essa modificação é imprescindível para qualquer reforma sindical, pois, apenas com a alteração do art. $8^{\circ}$ seria possível a ratificação da convenção supracitada.

17. Reconhecer a liberdade sindical pressupõe assegurar um direito humano, deve ser dado a empregados e empregadores a liberdade para se organizarem livremente sem quaisquer intervenções do Estado, gozar dessa ampla liberdade pressupõe poderem filiar-se e manter-se filiados aos sindicatos, desde que haja um interesse das partes. A liberdade sindical no Brasil pressupõe a ratificação da Convenção n. 87 da OIT.

\section{Referências}

ALEXY, Robert. Teoria geral dos direito fundamentais. Tradução Virgílio Afonso da Silva da $5^{a}$ edição alemã. São Paulo: Malheiros Editores, 2006.

ALMEIDA, R. R. O modelo sindical brasileiro é corporativista, pós-corporativista ou semicorporativista. Revista LTr. Legislação do Trabalho, v. 77, p. 07-15, 2013.

. Direitos laborais inespecíficos dos trabalhadores. Revista LTr. Legislação do Trabalho, v. 76, p. 295-296, 2012.

. Eficácia dos direitos fundamentais nas relações de trabalho. Revista LTr. Legislação do Trabalho, v. Ano 76, p. 647-650, 2012.

A descentralização do nível da negociação coletiva para o âmbito da empresa. LTr. Suplemento Trabalhista, v. Ano 45, p. 367369, 2009.

. Visão histórica da liberdade sindical. Revista LTr. Legislação do Trabalho, São Paulo, v. Ano 70, n.01/03/2006, p. 363-366, 2006.

Da intervenção administrativa em sindicato - a estrutura da clt em face das normas internacionais. Revista LTr Vol. 38.

ARAUJO, Luiz Alberto David. NUNES JR, Vidal Serrano. Curso de direito constitucional. $15^{\mathrm{a}}$ ed. São Paulo: Verbatim, 2011.

AROUCA, José Carlos. Curso básico de direito sindical. $2^{\mathrm{a}}$.ed, São Paulo: LTr, 2009.

BARROS, Alice Monteiro de. Curso de direito do trabalho. $7^{a}$ ed. São Paulo, LTr, 2011.

BRANDÃO, Adelino. Liberdade sindical e sociologia do trabalho. $7^{\text {a }}$ ed. Campinas: Julex livros, 1988.

BRITO FILHO, José Cláudio Monteiro de. Direito sindical. $3^{a}$ ed. São Paulo, LTr, 2009.

CANOTILHO, Joaquim José Gomes; Moreira, Vital. Constituição da república portuguesa anotada. $3^{\mathrm{a}}$ ed. Coimbra:1993. 
CÓRDOVA, Efrén. A organização sindical brasileira e a convenção 87 da OIT. Ministério do Trabalho; São Paulo: IBRART, 1984.

DELGADO, Godinho Maurício. Curso de direito do trabalho. 6a. ed. São Paulo: LTr, 2007.

MORAES, Alexandre. Constituição do Brasil interpretada. $4^{a}$ ed. São Paulo: Atlas, 2003.

NASCIMENTO, Amauri Mascaro do. Compêndio de direito sindical. $5^{a}$ Ed. São Paulo: LTr, 2008. PRADO JÚNIOR, Caio. O que é liberdade. Capitalização x Socialismo. São Paulo: Brasiliense, 2008. ROMITA, Arion Sayão. Direitos fundamentais nas relações de trabalho. $3^{a}$ ed. São Paulo: LTr, 2009.
SANTOS, Luiz Alberto Matos dos. A liberdade sindical como um direito fundamental. São Paulo: LTr, 2009.

SUSSEKIND, Arnaldo. Direito constitucional do trabalho. $4^{\text {a }}$.ed (ampl. e atual.). Rio de Janeiro: Renovar, 2010.

VASCONCELOS FILHO, Oton de Albuquerque. Liberdades sindicais e atos anti-sindicais. São Paulo: LTr, 2008.

http://www.planalto.gov.br/ccivil_03/constituicao/constituicao24.htm

http://www.planalto.gov.br/ccivil_03/decreto/ Antigos/D0979.htm

http://www6.senado.gov.br/legislacao/ListaPublicacoes.action? $\mathrm{id}=55323$ 